\title{
Improving the Accuracy of Using Pyranometers to Measure the Clear Sky Global Solar Irradiance
}

Ibrahim Reda

National Renewable Energy Laboratory 1617 Cole Boulevard

Golden, CO 80401

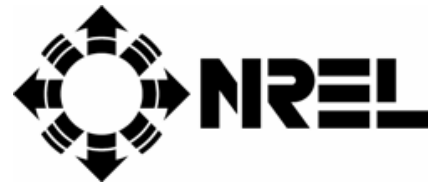

National Renewable Energy Laboratory 1617 Cole Boulevard Golden, Colorado 80401-3393

A national laboratory of the U.S. Department of Energy Managed by Midwest Research Institute for the U.S. Department of Energy under contract No. DE-AC36-83CH10093 


\section{Improving the Accuracy of Using Pyranometers to Measure the Clear Sky Global Solar Irradiance}

Ibrahim Reda

National Renewable Energy Laboratory

1617 Cole Boulevard

Golden, CO 80401

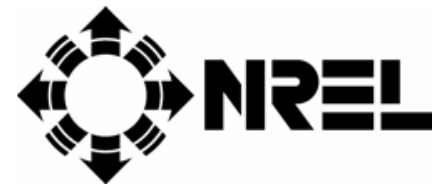

National Renewable Energy Laboratory 1617 Cole Boulevard Golden, Colorado 80401-3393

A national laboratory of the U.S. Department of Energy Managed by Midwest Research Institute for the U.S. Department of Energy under contract No. DE-AC36-83CH10093

Prepared under Task No. 56002010 June 1998 


\section{NOTICE}

This report was prepared as an account of work sponsored by an agency of the United States government. Neither the United States government nor any agency thereof, nor any of their employees, makes any warranty, express or implied, or assumes any legal liability or responsibility for the accuracy, completeness, or usefulness of any information, apparatus, product, or process disclosed, or represents that its use would not infringe privately owned rights. Reference herein to any specific commercial product, process, or service by trade name, trademark, manufacturer, or otherwise does not necessarily constitute or imply its endorsement, recommendation, or favoring by the United States government or any agency thereof. The views and opinions of authors expressed herein do not necessarily state or reflect those of the United States government or any agency thereof. 


\begin{abstract}
Pyranometer users have customarily applied one responsivity value when calculating the global solar irradiance. Usually, the responsivity value is reported by either the manufacturer or a calibration facility. Many pyranometer calibrations, made both at NREL and elsewhere, have shown that the responsivity of a pyranometer changes with the change in solar zenith and azimuth angles. Depending on how well the pyranometer sensor is radiometrically leveled, these changes can exceed $\pm 5 \%$ of the reported responsivity, which means that errors in the calculated global solar irradiance can exceed $\pm 5 \%$ from the nominal values. This paper describes a method to decrease the errors resulting from the change of the solar zenith angle under clear sky conditions. Two responsivity functions, morning and afternoon, were used instead of one responsivity value. The two functions have been chosen because of asymmetry of the morning and afternoon cosine responses demonstrated by some pyranometers.
\end{abstract}




\section{Acknowledgments}

I wish to thank Cecile Warner for making this publication possible; my colleagues, Daryl Myers and Tom Stoffel, for their continuous radiometry contributions and teachings; and my colleague, Steve Wilcox, for developing the RCC software that made this paper possible.

Additionally, I would like to thank NREL staff members who provided help with this publication, specifically Bev Kay and Rene Howard. 


\section{Contents}

\section{Chapter}

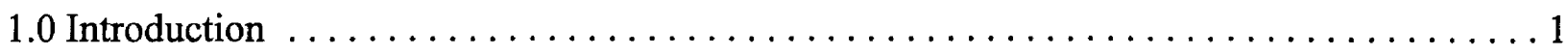

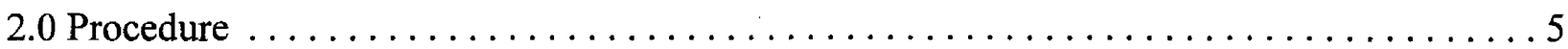

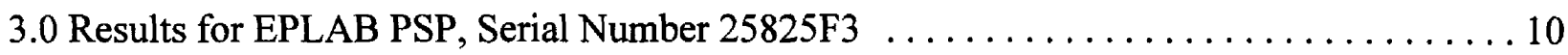

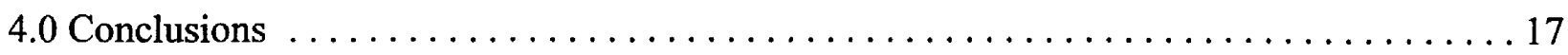

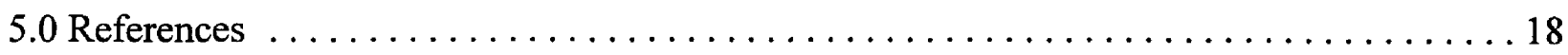

\section{Tables}

Table 1.1 Bin versus Responsivity for EPPLEY PSP 25825F3 from BORCAL9702 Report . . 1

Table 3.1.1 Data Points Used to Solve the Equations $\ldots \ldots \ldots \ldots \ldots \ldots \ldots \ldots \ldots \ldots \ldots$

Table 3.2.1 Morning and Afternoon Coefficients for $25825 \mathrm{~F} 3 \ldots \ldots \ldots \ldots \ldots \ldots \ldots \ldots$

Table 3.4.1 Percentage Errors Resulting from Using $\mathrm{RS}_{45-55}$ and Functions RS( $\theta$ ) for 25825F3. 12

\section{Figures}

Figure 1.1 Responsivity versus zenith angle for $25825 \mathrm{~F} 3$, from BORCAL9702. . . . . . . 2

Figure 1.2 An example of a pyranometer with a radiometrically unleveled sensor. . . . . . . 4

Figure 3.3.1 Measured and fitted responsivities versus zenith angle for $25825 \mathrm{~F} 3$, from BORCAL9702 ........................................ 13

Figure 3.3.2 Measured and fitted responsivities versus time for 25825F3, from BORCAL9702.14

Figure 3.4.1 Percentage errors resulting from using responsivity of zenith angle range, $45^{\circ}-55^{\circ}$, and responsivity as a function of zenith angle versus zenith angle for $25825 \mathrm{~F} 3 \ldots \ldots 15$

Figure 3.4.2 Percentage errors resulting from using responsivity of zenith angle range, $45^{\circ}-55^{\circ}$, and responsivity as a function of zenith angle versus time for $25825 \mathrm{~F} 3 \ldots \ldots \ldots 16$ 


\subsection{Introduction}

Pyranometers are used to measure the total hemispheric, broadband, shortwave solar irradiance, also called global irradiance. NREL calibrates pyranometers using the component summation technique [1]. In this technique, global irradiance equals the normal incident component plus the diffuse sky irradiance, where the normal incident component is the beam irradiance (direct normal) times the cosine of the solar zenith angle. The procedure NREL uses for such calibrations is called Broadband Outdoor Radiometer Calibration (BORCAL). At every calibration event, BORCAL can calibrate and characterize up to 90 radiometers under natural, clear sky conditions. Different types of radiometers can be accommodated, such as the EPPLEY PSP (Precision Spectral Pyranometer) and NIP (Normal Incidence Pyrheliometer), KIPP \& ZONEN and LICOR radiometers. The software used to acquire the data, calculate responsivities, and print the final BORCAL report is called Radiometer Calibration and Characterization (RCC) software [2]. An example of a reported responsivity from an RCC BORCAL report for a pyranometer is shown in Table 1.1 and Figure 1.1. The reported responsivities were calculated from data collected on June 26 and 30 and July 1, 2, 3 and 4, 1997.

Table 1.1 Bin versus Responsivity for EPPLEY PSP 25825F3 from BORCAL9702 Report

\begin{tabular}{|c|c|c|}
\hline \multicolumn{2}{|c|}{ Bin } & \multirow{2}{*}{$\mathrm{RS}\left(\mu \mathrm{V} / \mathrm{W} / \mathrm{m}^{\wedge} 2\right)$} \\
\hline Bin Number & Bin Range $\left({ }^{\circ}\right)$ & \\
\hline 1 & 0 to 9 & \\
\hline 2 & 9 to 18 & 9.681 \\
\hline 3 & 18 to 27 & 9.669 \\
\hline 4 & 27 to 36 & 9.639 \\
\hline 5 & 36 to 45 & 9.583 \\
\hline 6 & 45 to 54 & 9.533 \\
\hline 7 & 54 to 63 & 9.501 \\
\hline 8 & 63 to 72 & 9.546 \\
\hline 9 & 72 to 81 & 9.477 \\
\hline \multirow[t]{2}{*}{10} & 81 to 90 & 9.422 \\
\hline & 45 to 55 & 9.530 \\
\hline
\end{tabular}

Where:

- Bin is a zenith angle range of $9^{\circ}$, the $0^{\circ}$ to $90^{\circ}$ range is divided into 10 bins

- RS is the responsivity of the pyranometer in $\mu \mathrm{V} / \mathrm{W} / \mathrm{m}^{2}$, at each bin. 


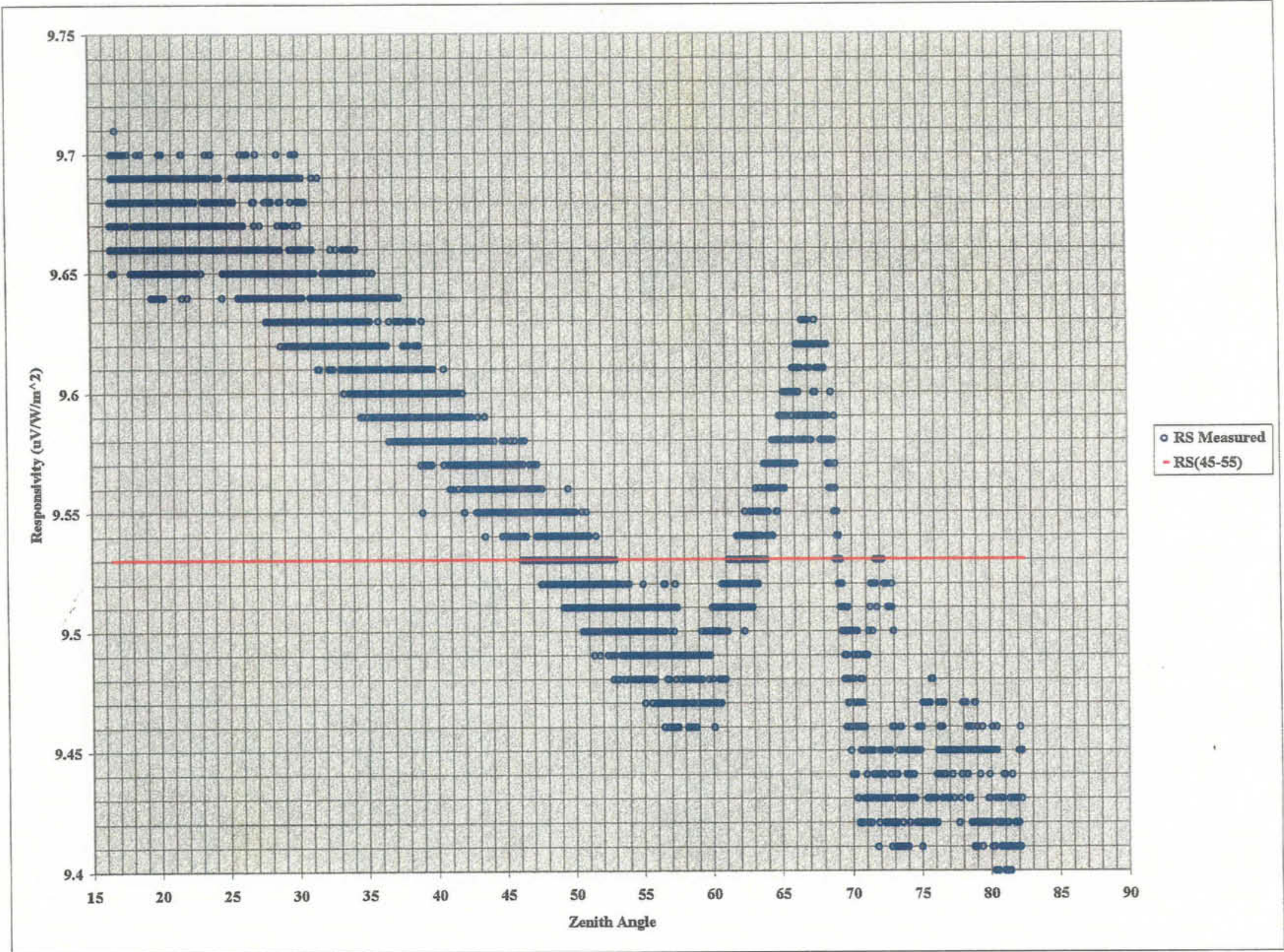

Figure 1.1 Responsivity versus zenith angle for $25825 \mathrm{~F} 3$, from BORCAL9702 
Pyranometer users have customarily applied the responsivity for the range from $45^{\circ}$ to $55^{\circ}$ to calculate the global solar irradiance.

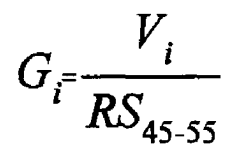

Where:

- $\mathrm{G}_{\mathrm{i}}$ is the $\mathrm{i}^{\text {th }}$ calculated global solar irradiance in $\mathrm{W} / \mathrm{m}^{2}$

- $\mathrm{V}_{\mathrm{i}}$ is the $\mathrm{i}^{\text {th }}$ output voltage of the pyranometer in microvolts $(\mu \mathrm{V})$

- $\mathrm{RS}_{45-55}$ is the responsivity at solar zenith angle range from $45^{\circ}$ to $55^{\circ}$ in $\mu \mathrm{V} / \mathrm{W} / \mathrm{m}^{2}$.

From Table 1.1 and Figure 1.1, one can note that the responsivity of the pyranometer changes with zenith angle. Thus, using one responsivity, $\mathrm{RS}_{45-55}$, can introduce errors into the global irradiance calculation.

The change of responsivity versus zenith angle is called the cosine response. The cosine response is unique for each pyranometer. It depends on how well the sensor is leveled during assembly, the resolution of the spirit bubble level in the base of the pyranometer, and the surface roughness of the sensor. Figure 1.2 shows an example of a pyranometer with an unleveled sensor. In this case, if one responsivity value were used, the resulting errors are from $-5 \%$ to $1.7 \%$ in global irradiance measurements.

This method can reduce these errors in global solar irradiance measurements, using pyranometers, by using a function of responsivity versus zenith angle. Because of the asymmetry between the morning and afternoon cosine response for a pyranometer [2], two functions, $\operatorname{RS}_{\mathrm{am}}(\theta)$ and $\operatorname{RS}_{\mathrm{pm}}(\theta)$, were chosen to fit the morning and the afternoon responsivity versus zenith angle. Then, the global solar irradiance is calculated in the morning, using the following equation:

$$
G_{i}=\frac{V_{i}}{R S_{a m}\left(\theta_{i}\right)}
$$

Where:

- $\mathrm{G}_{\mathrm{i}}$ is the $\mathrm{i}^{\text {th }}$ global solar irradiance reading in $\mathrm{W} / \mathrm{m}^{2}$

- $\mathrm{V}_{\mathrm{i}}$ is the $\mathrm{i}^{\text {th }}$ output voltage of the pyranometer in microvolts $(\mu \mathrm{V})$

- $\mathrm{RS}_{\mathrm{am}}\left(\theta_{\mathrm{i}}\right)$ is the pyranometer's responsivity calculated by substituting the $\mathrm{i}^{\text {th }}$ zenith angle, $\theta$, in the morning function $\mathrm{RS}_{\mathrm{am}}(\theta)$.

In the afternoon, the global solar irradiance is calculated using equation 1.2 and substituting $\operatorname{RS}_{\mathrm{am}}\left(\theta_{\mathrm{i}}\right)$ by $\mathrm{RS}_{\mathrm{pm}}\left(\theta_{\mathrm{j}}\right)$.

In order to calculate the coefficients of each fitting function, a number of data points are chosen, at a $5^{\circ}$ zenith angle increment. The data points are then substituted in the function. This will form a set of $(n+1)$ equations with $(n+1)$ unknown coefficients. Matrices are then used to solve the $(n+1)$ equations. 


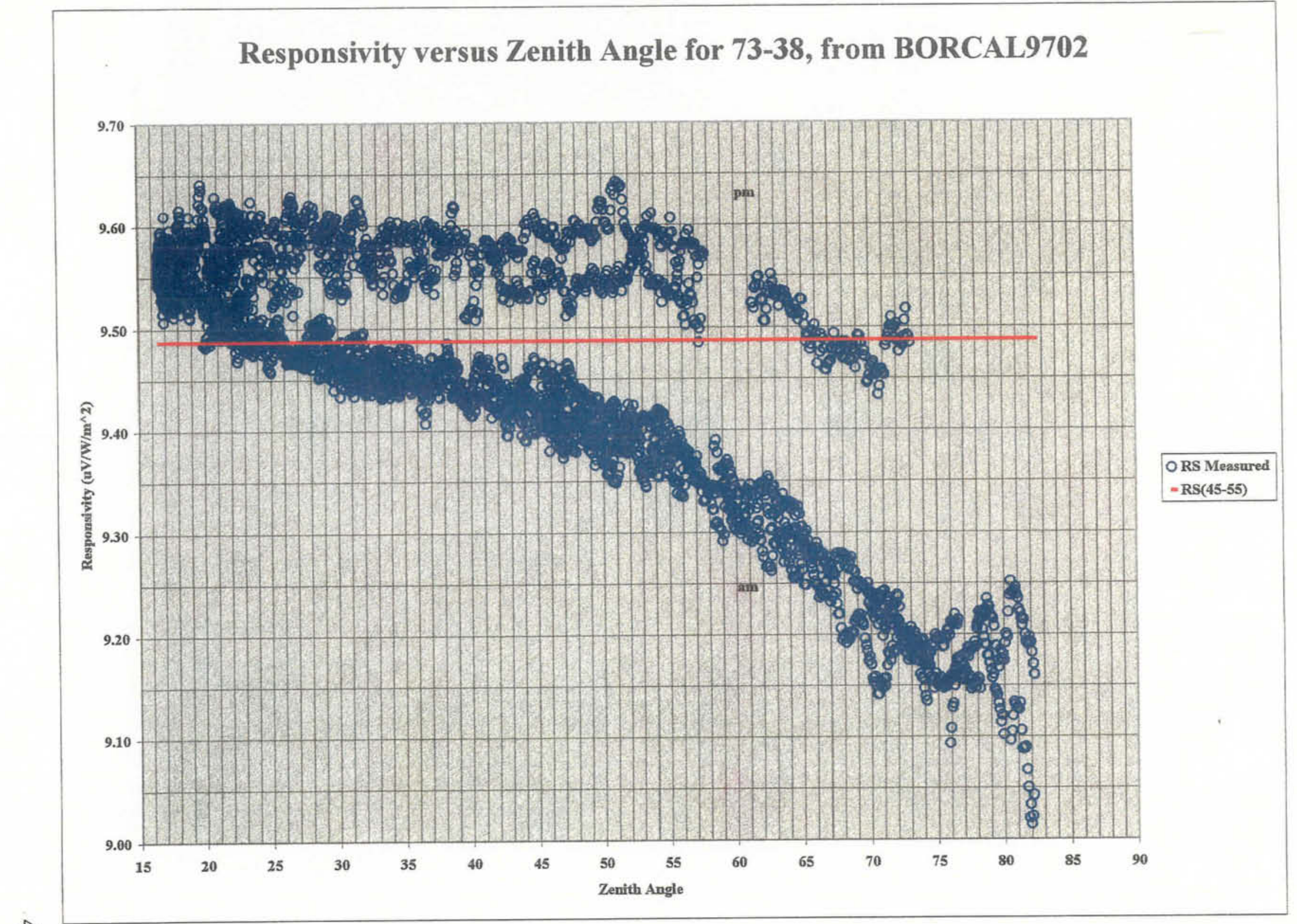

Figure 1.2 An example of a pyranometer with a radiometrically unleveled sensor 


\subsection{Procedure}

2.1 Because of the cosine behavior of the responsivity versus zenith angle, the following two cosine functions were chosen:

$$
\begin{aligned}
& R S_{a m}(\theta)=\sum_{i=0}^{n} a_{i} * \cos ^{i} \theta_{i, a m} \\
& R S_{p m}(\theta)=\sum_{j=0}^{m} p_{j} * \cos ^{j} \theta_{j, p m}
\end{aligned}
$$

Where:

- $\operatorname{RS}_{\mathrm{am}}(\theta)$ and $\mathrm{RS}_{\mathrm{pm}}(\theta)$ are the morning and afternoon responsivity functions of a pyranometer, respectively

- $\mathrm{n}$ and $\mathrm{m}$ are the number of morning and afternoon data points used to solve the $(n+1)^{\text {th }}$ and $(m+1)^{\text {th }}$ order equations, respectively

- $a_{i}$ and $p_{j}$ are the $i^{\text {th }}$ morning and $j^{\text {th }}$ afternoon coefficients, respectively

- $\theta_{\mathrm{i}, \mathrm{am}}$ and $\theta_{\mathrm{j}, \mathrm{pm}}$ are the $\mathrm{i}^{\text {th }}$ morning and $\mathrm{j}^{\text {th }}$ afternoon zenith angles, respectively.

2.2 Determine the data points used to solve equations 2.1.1 and 2.1.2. The data points can be chosen from an RCC BORCAL data file (responsivity versus zenith angle file) using the following procedure:

2.2.1 Divide the $0^{\circ}$ to $90^{\circ}$ zenith angle range into $5^{\circ}$ increments (i.e., $0^{\circ}, 5^{\circ}, 10^{\circ}, \ldots . ., 90^{\circ}$ )

2.2.2 Calculate the morning mean responsivity at each increment, $\mathrm{RS}_{\mathrm{f}, \mathrm{am}}$,

$$
R S_{f, a m}=\frac{\sum_{g=0}^{h} R S_{g, a m}}{h}
$$

Where:

- $\mathrm{RS}_{\mathrm{g}, \mathrm{am}}$ is the $\mathrm{g}^{\text {th }}$ morning responsivity in the range, $\mathrm{R}_{\mathrm{f}}$, e.g. $4.7^{\circ}$ to $5.3^{\circ}$

$$
f-0.3^{\circ} \leq R_{f} \leq f+0.3^{\circ}
$$

- $\mathrm{f}$ is the $\mathrm{f}^{\mathrm{th}}$ increment

- $h$ is the number of data points in the range, $R_{f}$. 
2.2.3 Calculate the standard deviation of $\mathrm{RS}_{\mathrm{f}, \mathrm{am}}, \mathrm{SD}_{\mathrm{f}, \mathrm{am}}$,

$$
S D_{f, a m}=\sqrt{\frac{\sum_{g=0}^{h}\left(R S_{g, a m}-R S_{f, a m}\right)^{2}}{h-1}}
$$

2.2.4 Reject all outlier responsivities, $\mathrm{RS}_{\text {reject, }}$

$$
R S_{f, a m}-3 * S D_{f, a m} \geq R S_{r e j e c t} \geq R S_{f, a m}+3 * S D_{f, a m}
$$

2.2.5 Recalculate $\mathrm{RS}_{\mathrm{f}, \mathrm{am}}$.

2.2.6 Repeat steps 2.2 .2 through 2.2 .5 until all outliers are rejected.

2.2.7 Repeat steps 2.2 .2 through 2.2 .6 to calculate the mean afternoon responsivity at each increment, $\mathrm{RS}_{\mathrm{f}, \mathrm{pm}}$.

2.2.8 Include all the peaks and valleys, if the responsivity versus zenith angle curve at zenith angles higher than $60^{\circ}$ is the same shape as Figure 1.1.

2.2.9 For the boundary conditions, include the data point at solar noon of the day the calibration was performed, for both the morning and afternoon data points. Also include the two data points for the largest zenith angles for the morning and afternoon data.

2.3 Substituting the chosen data points from step 2.2 in equations 2.1.1 and 2.1.2, one can calculate all the coefficients, $a_{j}$ 's and $p_{j}$ 's.

2.3.1 The following matrix equations were used to solve the $n+1$ equations, for the morning function, and the $\mathrm{m}+1$ equations, for the afternoon function[3]:

$$
\left[R S_{a m}\right]=[A] *\left[\cos \theta_{a m}\right]
$$

$$
\left[R S_{p m}\right]=[P] *\left[\cos \theta_{p m}\right]
$$


Where:

- matrix $\left[\mathrm{RS}_{\mathrm{am}}\right]$ is constructed in the form:

$$
\left[R S_{a m}\right]=\left[\begin{array}{c}
R S_{0, a m} \\
R S_{1, a m} \\
\cdot \\
\cdot \\
R S_{n, a m}
\end{array}\right]
$$

where, $\mathrm{RS}_{0, \mathrm{am}}$ to $\mathrm{RS}_{\mathrm{n}, \mathrm{am}}$, are the responsivities chosen, using step 2.2

- matrix $[\mathrm{A}]$ is constructed in the form:

$$
[A]=\left[\begin{array}{l}
a_{0} \\
a_{1} \\
\cdot \\
a_{n}
\end{array}\right]
$$

where, $a_{0}$ to $a_{n}$, are the unknown coefficients of the morning function $\operatorname{RS}_{a m}(\theta)$.

- matrix $\left[\cos \theta_{\text {am }}\right]$ is constructed in the form:

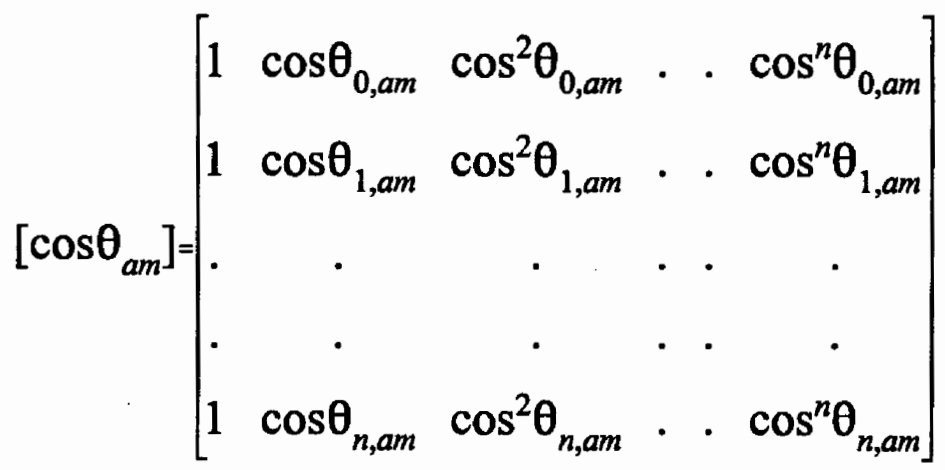

where, $\theta_{0, \mathrm{am}}$ to $\theta_{\mathrm{n}, \mathrm{am}}$, are the morning zenith angles chosen from step 2.2 .

The same procedure used to construct the morning matrices can be followed to construct the afternoon matrices. 
2.3.2 The following steps describe how to calculate the coefficients of the morning function, $\mathrm{RS}_{\mathrm{am}}(\theta)$. The same steps are followed to calculate the coefficients of the afternoon function, $\operatorname{RSpm}(\theta)[3]$.

2.3.2.1 Equation 2.3.1 can be rearranged to be,

$$
\left[R S_{a m}\right] *\left[\cos \theta_{a m}\right]^{-1}=[I] *[A]
$$

Where:

- $\left[\cos \theta_{\mathrm{am}}\right]^{-1}$ is the inverse (reciprocal) of matrix $\left[\cos \theta_{\mathrm{am}}\right]$

- [I] is the unit matrix.

2.3.2.2 Calculate $\left[\cos \theta_{\mathrm{am}}\right]^{-1}$ using the following steps:

- Construct the matrix of cofactors for matrix $\left[\cos \theta_{\mathrm{am}}\right],[\mathrm{M}]$,

$$
[M]=\left[\begin{array}{ccccc}
m_{00} & m_{01} & \cdot & \cdot & m_{0 n} \\
m_{10} & m_{11} & \cdot & \cdot & m_{1 n} \\
\cdot & \cdot & \cdot & \cdot & \cdot \\
\cdot & \cdot & m_{i j} & \cdot & \cdot \\
m_{n 0} & m_{n 1} & \cdot & \cdot & m_{n n}
\end{array}\right]
$$

where, $m_{i j}$ is a cofactor that equals the determinant value of the matrix formed by deleting row $i$ and column $\mathrm{j}$ of matrix $\left[\cos \theta_{\mathrm{am}}\right]$.

- Construct the adjoint of matrix $\left[\cos \theta_{\text {am }}\right]$, Adj. $\left[\cos \theta_{a m}\right]$,

$$
\operatorname{Adj} \cdot\left[\cos \theta_{a m}\right]=\left[\begin{array}{ccccc}
m_{00} & m_{10} & \cdots & m_{n 0} \\
m_{01} & m_{11} & \cdot & \cdot & m_{n I} \\
\cdot & \cdot & \cdot & \cdot & \cdot \\
\cdot & \cdot & \cdot & \cdot & \cdot \\
m_{0 n} & m_{1 n} & \cdot & m_{n n}
\end{array}\right]
$$


- Calculate the determinant value of matrix $\left[\cos \theta_{a m}\right], \Delta$,

$$
\Delta=\sum_{j=0}^{n}(-1)^{j} * \cos ^{j} \theta_{0, a m} * m_{0 j}
$$

Where:

- $\cos ^{\mathrm{j}} \theta_{0, a m}$ 's are the first raw of matrix [ $\cos \theta_{\text {am }}$ ], from equation 2.3.5

- $\mathrm{m}_{0 \mathrm{j}}$ 's are the cofactors of the first raw of matrix [M], from equation 2.3.7.

- Calculate the matrix $\left[\cos \theta_{\mathrm{am}}\right]^{-1}$,

$$
\left[\cos \theta_{a m}\right]^{-1}=\frac{1}{\Delta} * A d j \cdot\left[\cos \theta_{a m}\right]
$$

Matrix $\left[\cos \theta_{a m}\right]^{-1}$ will be in the following form:

$$
\left[\cos \theta_{a m}\right]^{-1}=\left[\begin{array}{ccccc}
z_{00, a m} & z_{01, a m} & \cdot & \cdot & z_{0 n, a m} \\
z_{10, a m} & z_{11, a m} & \cdot & \cdot & z_{1 n, a m} \\
\cdot & \cdot & \cdot & \cdot & \cdot \\
\cdot & \cdot & z_{i j, a m} & \cdot & \cdot \\
z_{n 0, a m} & z_{n l, a m} & \cdot & \cdot & z_{n n, a m}
\end{array}\right]
$$

where, $\mathrm{z}_{\mathrm{i}, \mathrm{jam}}$ is the element in the $\mathrm{i}^{\text {th }}$ raw of the $\mathrm{j}^{\text {th }}$ column of the matrix.

2.3.2.3 Substituting equations 2.3 .3 and 2.3.11 in equation 2.3.6, matrix [A] will yield the following:

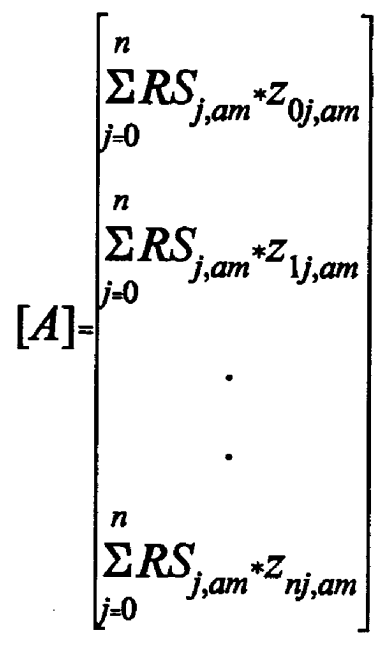


2.3.2.4 From equation 2.3.12, the morning function coefficients are:

$a_{0}=\sum_{j=0}^{n} R S_{j, a m} * z_{0 j, a m} \quad, \quad a_{1}=\sum_{j=0}^{n} R S_{j, a m} * z_{1 j, a m} \quad, \quad . \quad . \quad . \quad, \quad a_{n}=\sum_{j=0}^{n} R S_{j, a m} * z_{n j, a m}$

Similarly, the afternoon function coefficients are:

$p_{0}=\sum_{j=0}^{m} R S_{j, p m} * z_{0 j p m} \quad, \quad p_{1}=\sum_{j=0}^{m} R S_{j, p m} * z_{1 j p m} \quad, \quad . \quad . \quad . \quad, \quad p_{m}=\sum_{j=0}^{m} R S_{j, p m} * z_{m j p m}$

\subsection{Results for EPLAB PSP, Serial Number 25825F3}

3.1 Table 3.1.1 shows the chosen data points used for solving equations 2.3.1 and 2.3.2. Note that zenith angles $57.5^{\circ}$ and $61.5^{\circ}$ were chosen because data points around $60^{\circ}$ were missing.

Table 3.1.1 Data Points Used to Solve the Equations

\begin{tabular}{|c|c|c|c|c|c|}
\hline \multirow{2}{*}{$\begin{array}{c}\text { Zenith } \\
\left.\text { Angle( }{ }^{\circ}\right)\end{array}$} & \multicolumn{2}{|c|}{ Responsivity $\left(\mu \mathrm{V} / \mathrm{W} / \mathrm{m}^{2}\right)$} & \multirow{2}{*}{$\begin{array}{c}\text { Zenith } \\
\text { Angle( }{ }^{\circ} \text { ) }\end{array}$} & \multicolumn{2}{|c|}{ Responsivity $\left(\mu \mathrm{V} / \mathrm{W} / \mathrm{m}^{2}\right)$} \\
\hline & Morning & Afternoon & & Morning & Afternoon \\
\hline 20 & 9.657 & 9.679 & 57.5 & & 9.498 \\
\hline 25 & 9.665 & 9.66 & 60 & 9.491 & \\
\hline 30 & 9.637 & 9.661 & 61.5 & & 9.53 \\
\hline 35 & 9.614 & 9.621 & 65 & 9.574 & 9.584 \\
\hline 40 & 9.589 & 9.598 & 70 & 9.467 & 9.499 \\
\hline 45 & 9.558 & 9.563 & 75 & 9.44 & \\
\hline 50 & 9.529 & 9.533 & 80 & 9.433 & \\
\hline 55 & 9.494 & 9.501 & & & \\
\hline \multicolumn{3}{|c|}{ Responsivity at solar noon } & 16.5 & 9.67 & 9.67 \\
\hline \multicolumn{3}{|c|}{ Maximum morning responsivity } & 67.5 & 9.61 & \\
\hline \multicolumn{3}{|c|}{ Minimum morning responsivity } & 71.8 & 9.43 & \\
\hline \multicolumn{3}{|c|}{ Maximum afternoon responsivity } & 66.6 & & 9.62 \\
\hline \multicolumn{3}{|c|}{ Minimum afternoon responsivity } & 70.6 & & 9.48 \\
\hline \multicolumn{3}{|c|}{ Morning responsivity at greatest zenith angle } & 82.2 & 9.43 & \\
\hline \multicolumn{3}{|c|}{ Afternoon responsivity at greatest zenith angle } & 73 & & 9.51 \\
\hline
\end{tabular}


3.2 Table 3.2.1 shows the resultant morning and afternoon coefficients. Because the numbers are so large, it is important to use double precision numbers in the data processing. Labview software was used for this paper.

Table 3.2.1 Morning and Afternoon Coefficients for 25825F3

\begin{tabular}{||c|c|c||c|c|c||}
\hline Index & $\begin{array}{c}\text { Morning } \\
\text { Coefficients } \\
\left(\mathbf{a}_{\mathbf{i}}\right)\end{array}$ & $\begin{array}{c}\text { Afternoon } \\
\text { Coefficients } \\
\left(\mathbf{p}_{\mathbf{i}}\right)\end{array}$ & Index & $\begin{array}{c}\text { Morning } \\
\text { Coefficients } \\
\left(\mathbf{a}_{\mathbf{i}}\right)\end{array}$ & $\begin{array}{c}\text { Afternoon } \\
\text { Coefficients } \\
\left(\mathbf{p}_{\mathbf{i}}\right)\end{array}$ \\
\hline \hline 0 & 322.0557 & -177040.6421 & 9 & -10051108841 & 6218266505.218 \\
\hline 1 & -15340.3639 & 4380869.3172 & 10 & 10234305726 & 8230850516.817 \\
\hline 2 & 335132.3279 & -49189047.4696 & 11 & -4157036370.6 & -16754266146.5 \\
\hline 3 & -4316594.1507 & 331183115.551 & 12 & -5383059629.6 & 14738556229.14 \\
\hline 4 & 36609827.5220 & -1486510847.19 & 13 & 11400268630 & -7542415882.63 \\
\hline 5 & -216280857.64 & 4666092359.57 & 14 & -10312974037 & 2180603495.788 \\
\hline 6 & 917533664.659 & -10398110383.6 & 15 & 5409879832.5 & -277477554.087 \\
\hline 7 & -2833288139.8 & 16154549290.1 & 16 & -1599620089.6 & \\
\hline 8 & 6351005967.98 & -16016335476.3 & 17 & 207760813.39 & \\
\hline
\end{tabular}

3.3 For pyranometer PSP 25825F3, Figure 3.3.1 shows the responsivity versus zenith angle, measured through BORCAL9702, and the responsivity versus zenith angle using the two fitting responsivity functions, $\mathrm{RS}_{\mathrm{am}}(\theta)$ and $\mathrm{RS}_{\mathrm{pm}}(\theta)$. Figure 3.3.2 shows the responsivities versus the true solar time.

3.4 Figure 3.4.1 shows the percentage error in the global solar irradiance measurements, if one responsivity (e.g., responsivity at zenith angle range from $45^{\circ}$ to $55^{\circ}$ ) is used, and the percentage error if the two fitting responsivity functions, $\operatorname{RS}_{\mathrm{am}}(\theta)$ and $\mathrm{RS}_{\mathrm{am}}(\theta)$, are used. Figure 3.4.2 shows the errors versus the true solar time. The percentage errors are calculated as follows:

$$
E_{i, R S}=\frac{\left[\frac{V_{i}}{R S_{45-55}}-G_{i, r e f}\right] * 100}{G_{i, r e f}}
$$

Where:

- $\mathrm{E}_{\mathrm{i}, \mathrm{RS}}$ is the error of the $\mathrm{i}^{\text {th }}$ data point using one responsivity, $\mathrm{RS}_{45-55}$

- $\mathrm{G}_{\mathrm{i}, \mathrm{ref}}$ is the $\mathrm{i}^{\text {th }}$ reference global solar irradiance

- $V_{i}$ is the $i^{\text {th }}$ output voltage from the pyranometer, in microvolts

- $\mathrm{RS}_{45-55}$ is the responsivity of the pyranometer at $45^{\circ}$ to $55^{\circ}$ zenith angle bin. 
and,

$$
E_{i, a m, R S(\theta)}=\frac{\left[\frac{V_{i}}{R S_{a m}\left(\theta_{i}\right)}-G_{i, r e f}\right] * 100}{G_{i, r e f}}
$$

Where:

- $E_{i, a m, R S(\theta)}$ is the error of the $i^{\text {th }}$ data point using the morning responsivity function

- $\operatorname{RS}_{\text {am }}\left(\theta_{\mathrm{i}}\right)$ is the morning responsivity calculated by substituting $\theta$ by $\theta_{\mathrm{i}}$ in the morning responsivity function, $\operatorname{RS}_{\mathrm{am}}(\theta)$, where $\theta_{\mathrm{i}}$ is the $\mathrm{i}^{\text {th }}$ zenith angle.

The errors resulting from using the afternoon responsivity function, $\mathrm{E}_{\mathrm{j}, \mathrm{pm}, \mathrm{Rs}(\theta)}$, are calculated using equation 3.4 .2 by substituting $\mathrm{V}_{\mathrm{i}}$ and $\mathrm{RS}_{\mathrm{am}}\left(\theta_{\mathrm{i}}\right)$, by $\mathrm{V}_{\mathrm{j}}$ and $\mathrm{RS}_{\mathrm{pm}}\left(\theta_{\mathrm{j}}\right)$.

Table 3.4.1 shows the maximum and minimum percentage errors at zenith angle ranges $16.5^{\circ}$ to $45^{\circ}$ and $55^{\circ}$ to $82^{\circ}$.

Table 3.4.1 Percentage Errors Resulting from Using RS $_{45-55}$ and Functions RS $(\theta)$ for $25825 F 3$

\begin{tabular}{|c|c|c|c|c|}
\hline \multirow{2}{*}{$\begin{array}{c}\text { Zenith Angle } \\
\text { Range }\end{array}$} & \multicolumn{2}{|c|}{ Using $\mathrm{RS}_{45-55}$} & \multicolumn{2}{c|}{ Using $\mathrm{RS}_{\mathrm{am}}(\theta)$ and $\mathrm{RS}_{\mathrm{pm}}(\theta)$} \\
\cline { 2 - 5 } & Maximum Error & Minimum Error & Maximum Error & Minimum Error \\
\hline $16.5^{\circ}$ to $45^{\circ}$ & 1.85 & 0.3 & 0.5 & -0.5 \\
\hline $55^{\circ}$ to $82^{\circ}$ & 1.05 & -1.4 & 0.6 & -0.65 \\
\hline
\end{tabular}




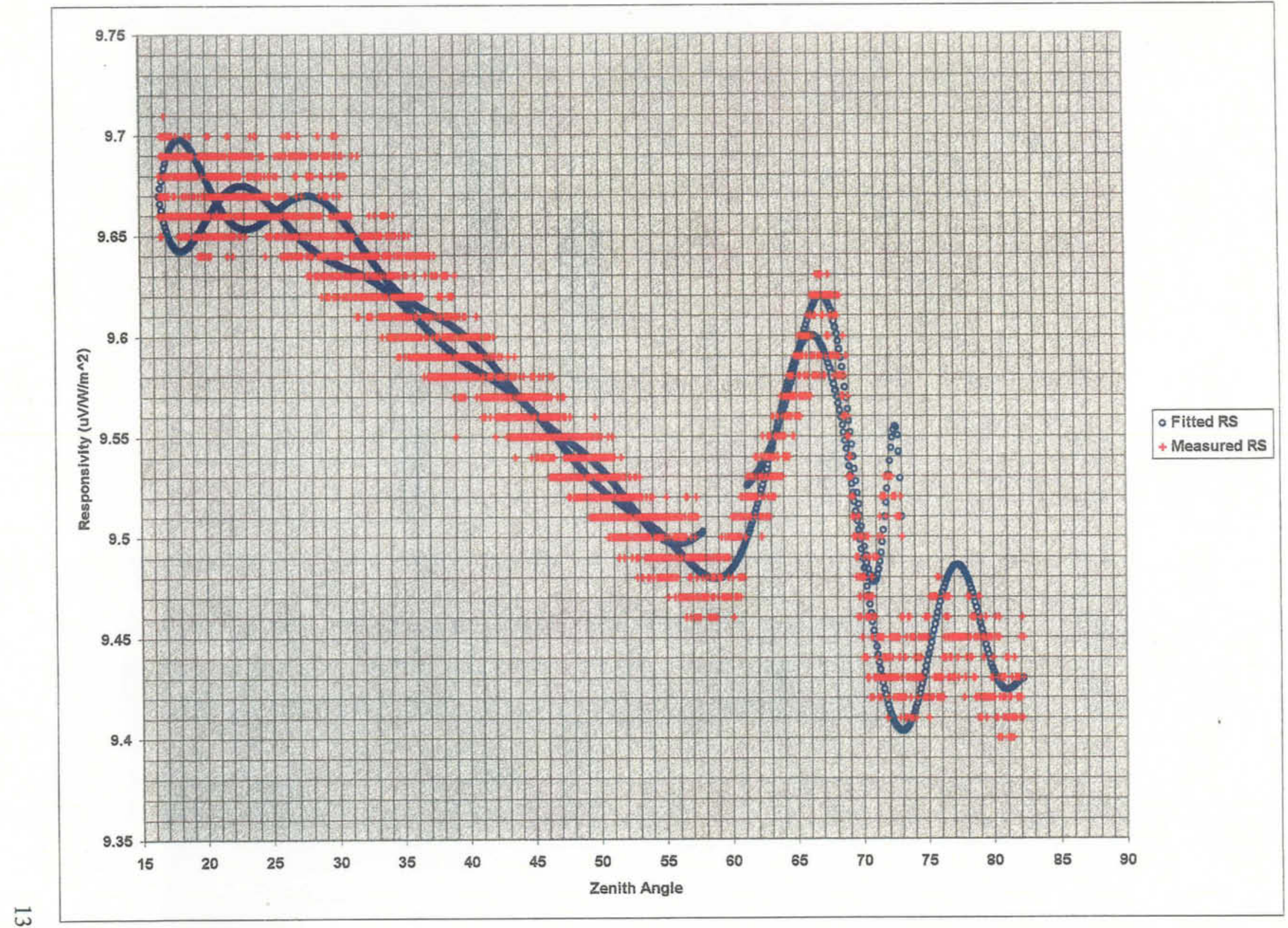

Figure 3.3.1 Measured and fitted responsivities versus zenith angle for 25825F3, from BORCAL9702 


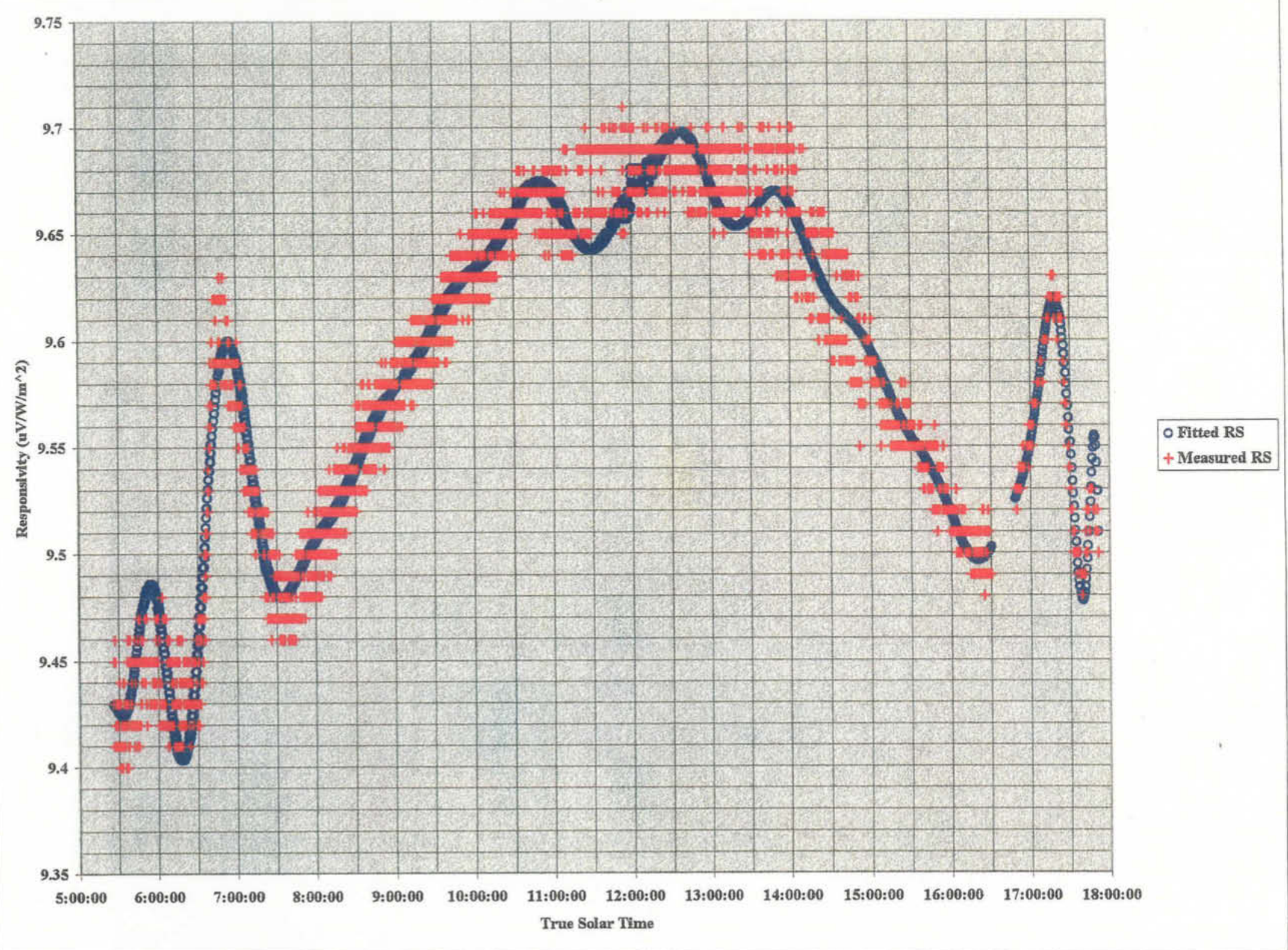

Figure 3.3.2 Measured and fitted responsivities versus time for $25825 \mathrm{~F}$, from BORCAL9702 


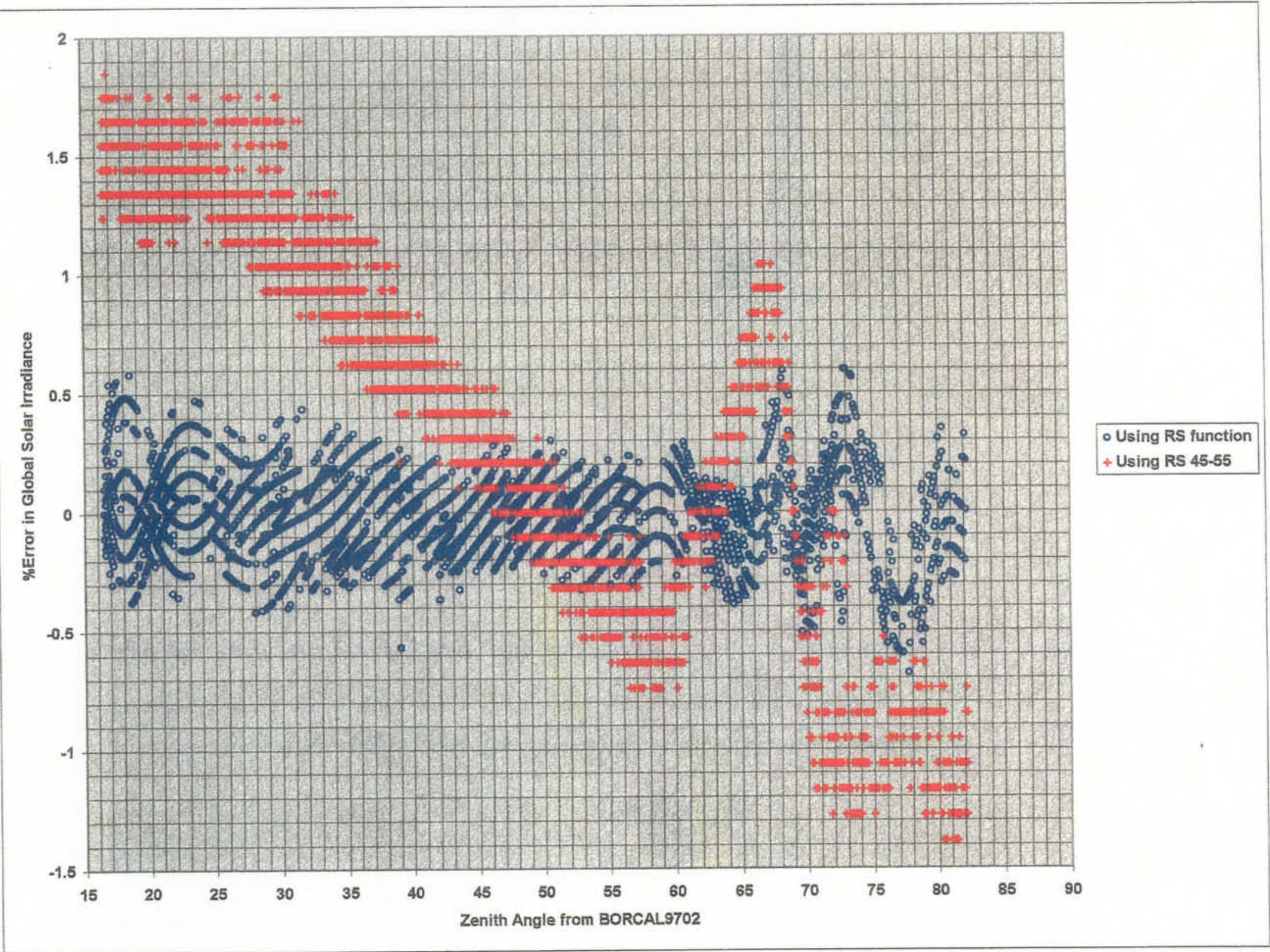

Figure 3.4.1 Percentage errors resulting from using responsivity of zenith angle range, 45-55, and responsivity as a function of zenith angle versus zenith angle for $25825 \mathrm{~F} 3$ 


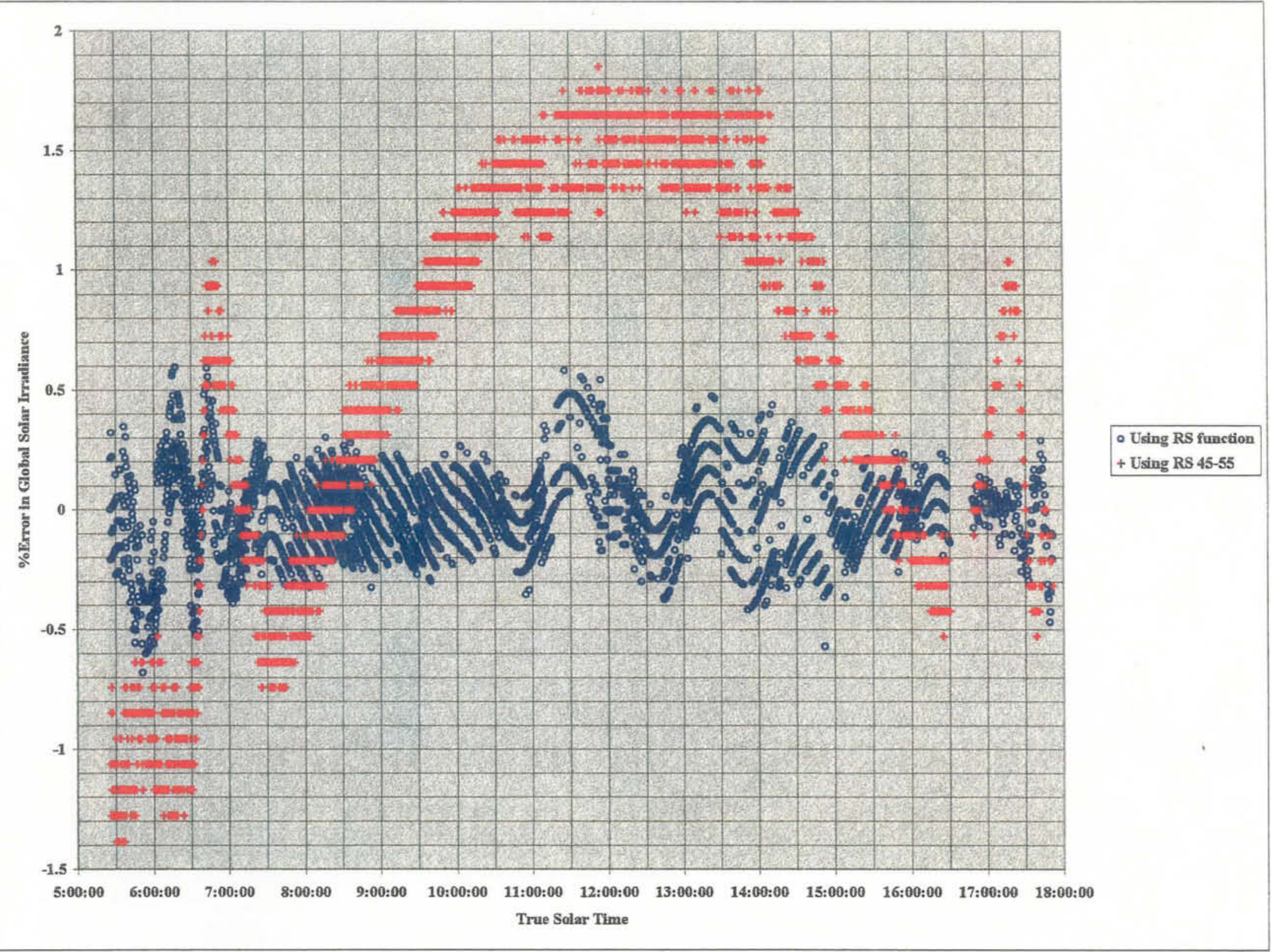

Figure 3.4.2 Percentage errors resulting from using responsivity of zenith angle range, 45-55, and resonsivity as a function of zenith angle versus time for $25825 \mathrm{~F} 3$ 


\subsection{Conclusions}

4.1. Figure 3.4.1 and Table 3.4.1 show that the values of percentage errors resulting from using $\mathrm{RS}_{45-55}$ are larger than the percentage errors that result from using the two responsivity functions, $\operatorname{RS}_{\mathrm{am}}(\theta)$ and $\mathrm{RS}_{\mathrm{pm}}(\theta)$. The table and figure also show that the errors are increasing outside the zenith angle range from $45^{\circ}$ to $55^{\circ}$ when $\mathrm{RS}_{45-55}$ is used, but the errors stayed about the same using the two responsivity functions, $\operatorname{RS}_{\mathrm{am}}(\theta)$ and $\mathrm{RS}_{\mathrm{pm}}(\theta)$.

4.2. Using the two responsivity functions will improve the accuracy of measuring the global solar irradiance, in the example of $25825 \mathrm{~F} 3$, by at least $68 \%$ in certain zenith angle ranges.

$$
\text { Improvement }=\frac{(1.58-0.5) * 100}{1.58}=68 \%
$$

Where:

- 1.58 is the maximum percentage error that results from using $\mathrm{RS}_{45-55}$ at zenith angle range $16.5^{\circ}$ to $45^{\circ}$ from Table 3.4 .1

- 0.5 is the maximum percentage error that results from using the two morning and afternoon functions from Table 3.4.1.

The improvement can be much better than $68 \%$ for pyranometers with sensors that are not radiometrically leveled. The uncertainty of these pyranometers can reach $\pm(5$ to 10$) \%$ if $\mathrm{RS}_{45-55}$ is used to calculate the global solar irradiance from sunrise to sunset.

4.3 The two responsivity functions, $\operatorname{RS}_{\mathrm{am}}(\theta)$ and $\mathrm{RS}_{\mathrm{pm}}(\theta)$, are only valid between and at the boundary conditions. For this reason, it is important to calibrate the pyranometer from sunrise to sunset in order to cover the zenith angle range from $0^{\circ}$ to $90^{\circ}$. If zenith angle at solar noon does not reach $0^{\circ}$ on the day of calibration or if calibration were stopped before $90^{\circ}$ is reached, extreme care should be taken in estimating data points outside the boundary conditions, to cover the range $0^{\circ}$ to $90^{\circ}$. These estimated data points can then be included in the data set (see Table 3.1.1), used to calculate the morning and afternoon coefficients of the functions $\operatorname{RS}_{\mathrm{am}}(\theta)$ and $\mathrm{RS}_{\mathrm{pm}}(\theta)$.

4.4 This paper describes the first step toward improving the uncertainty of measuring the clear sky global solar irradiance. The second step is to develop two responsivity functions, $\operatorname{RS}_{\mathrm{am}}(\theta, \phi)$ and $\operatorname{RS}_{\mathrm{pm}}(\theta, \phi)$, where $\phi$ is the solar azimuth angle, to include the azimuthal response of a pyranometer. This was not discussed in this paper because of the complexity of the functions and the lack of calibration data from different days of the year. More calibrations from different days of the year are recommended to describe the zenith and azimuthal responses more accurately for a pyranometer. 


\subsection{References}

1. Myers, D.R., Emery, K. and Stoffel, T.L., 1984, Uncertainty Estimates for Global Solar Irradiance Measurements Used to Evaluate PV Device Performance, Solar Cells, 27, 1987, p. 456 .

2. National Renewable Energy Laboratory (NREL), NREL BORCAL reports, Golden, CO: NREL.

3. ONeil, P.V., 1995, Advanced Engineering Mathematics, fourth edition, Boston, MA: PWS Publishing Company, pp. 316-397. 